\title{
Goldenhar Syndrome- A Case Report
}

\author{
Sahil Arora ${ }^{1}$, Rohan Sood ${ }^{2}$, Ishman K Chopra ${ }^{3}$, P.K.Manjhi ${ }^{4}$, Punita Garg ${ }^{5}$ \\ Department Of Ophthalmology, MMIMSR, Mullana, Ambala, Haryana, India
}

\begin{abstract}
Goldenhar syndrome is a birth defect resulting from the maldevelopment of the first two branchial arches with incomplete development of the ear, nose, soft palate, lip and mandible. The phenotype is highly variable. Goldenhar syndrome is one of the variants of craniofacial anomalies. It is unilateral in $70-80 \%$ of the cases. It is known as oculoauriculo vertebral (OAV) dysplasia. The syndrome complex includes limbaldermoid or lipodermoid, pre-auricular tags, hemifacial asymmetry and vertebral anomalies. These are the common anomalies of the condition.This work reports a case 14 year old male in ophthalmology department of MMIMSR who presented with limbaldermoid and on evaluation was found to have the classical signs of this syndrome. Also included is the current protocol for treatment of this syndrome.
\end{abstract}

Keywords: Goldenhar syndrome, limbaldermoid, epibulbardermoid

\section{Introduction}

Goldenhar syndrome is a birth defect resulting from the maldevelopment of the first two branchial arches with incomplete development of the ear, nose, soft palate, lip and mandible. The phenotype is highly variable $^{1}$. The syndrome was first recorded by German physician Carl Ferdinand Von Arlt in 1845, however, when Maurice Goldenhar described its various characteristic features in 1952, the credit of discovery went to him. In 1963, Gorlin named this syndrome as oculoauriculovertebral. It consists classically of the triad of (usually unilateral) maldevelopment of the first and second branchial arches, occulardermoids, and vertebral anomalies ${ }^{2,3}$. It is unilateral in $70-80 \%$ of the cases ${ }^{4}$.Its prevalence rate is $1-9 /$ per $100000^{5,6}$ and incidence rate is 1 per 25000-45000 births $^{7}$. Male is more commonly affected than the female (ratio 2:1). Most of the cases of $\mathrm{OAV}$ are sporadic, autosomal dominant transmission is reported for $1 \%-2 \%$ of the cases. A few cases with autosomal recessive inheritance have been reported ${ }^{8}$.Though, the etiology of Goldenhar syndrome is not well established, it is thought to be due to exposure to various viruses or chemicals during pregnancy. Some researchers also suggested gestational diabetes mellitus as one of the cause. The MSX homeobox genes play a crucial role in the pathogenesis ${ }^{3,9}$. Ocular anomalies occur in about $50 \%$ of the cases of $\mathrm{OAV}^{6}$.Epibulbardermoid and lipodermoid are the most common. Coloboma of the upper eyelid may be present. Limbaldermoid or lipodermoid are mainly located in the inferotemporal region of the eye. Ocular defects are reported in $65 \%$ of the cases and include pre-auricular tags, microtia, anotia and conductive hearing loss. Vertebral anomalies are combination of hemivertebra, fused ribs, kyphosis and scoliosis. Additional featuressuch as cardiac, genito-urinary and pulmonary systems can also be affected ${ }^{10,11}$.

Case report:-A 14 years old male reported at the Ophthalmology OPD of MMIMSR, Mullana (Ambala), Haryana, with complaints of growth of mass in left eye \& decrease in vision associated with preauriculartags(fig.1). The mass was present inferotemporally on the limbus encroaching the cornea and was gradually increasing and causing obstruction of the visual axis.

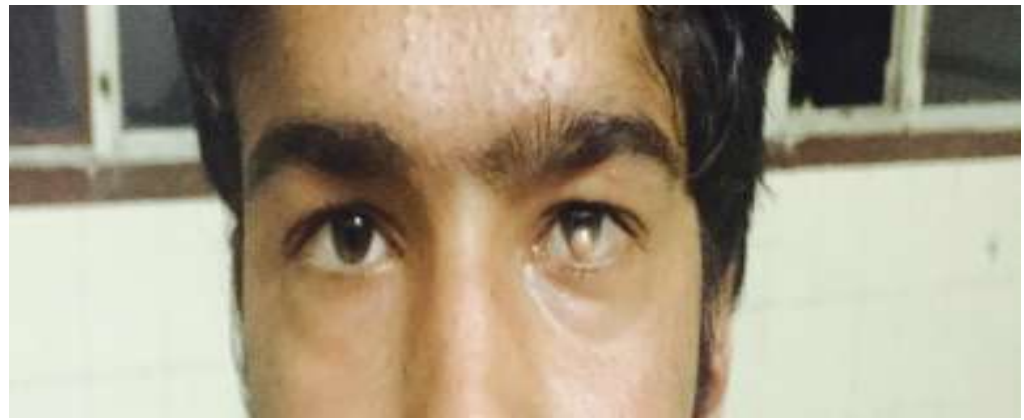

Figure 1. Case reported in the opd

The patient was examined thoroughly. His visual acuity was $6 / 6$ in right eye and 2/60 in left eye. After slit lamp examination it was revealed that the mass was limbal-dermoid (Fig.2).Fundoscopic examination was found normal. 


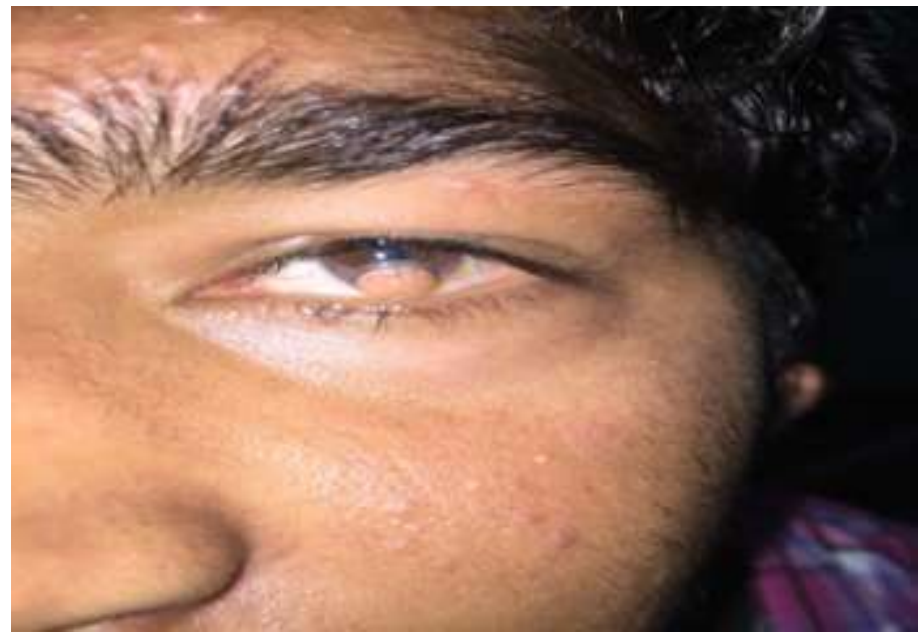

Figure 2.Limbaldermoid in left eye

ENT examination revealed preauricular tags present in the both ears(Fig. 3). No other abnormalities were detected. Systemic examination like cardiovascular, pulmonary and genito-urinary systems was done but no abnormalities were detected. The laboratory investigations were within normal limits. Electrocardiography was normal. X-Ray of the vertebral column showed scoliosis as a classical feature (Fig. 4).

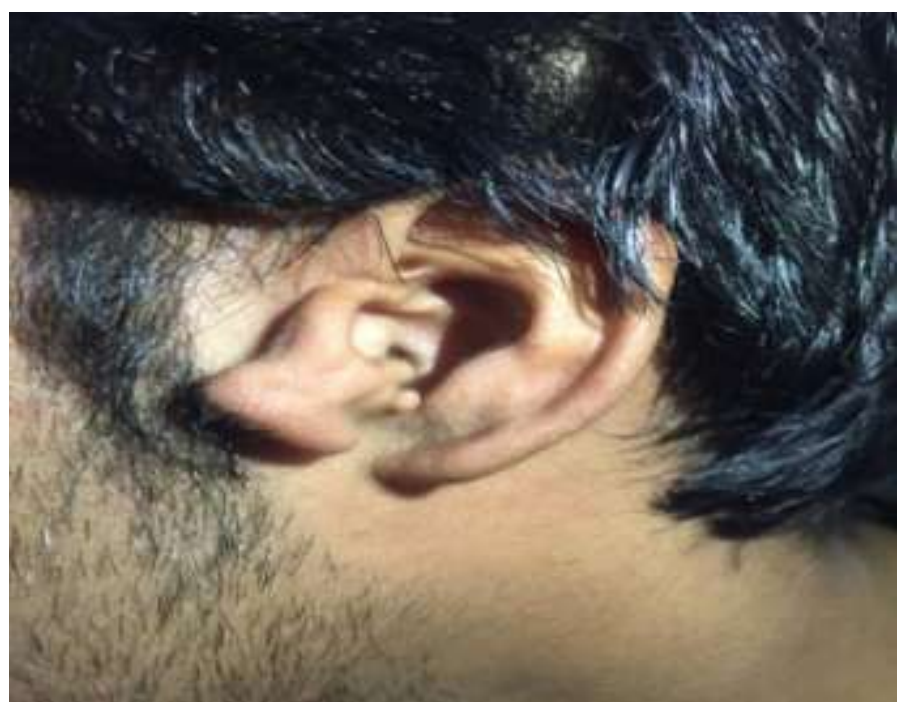

Figure 2.Preauricular tags

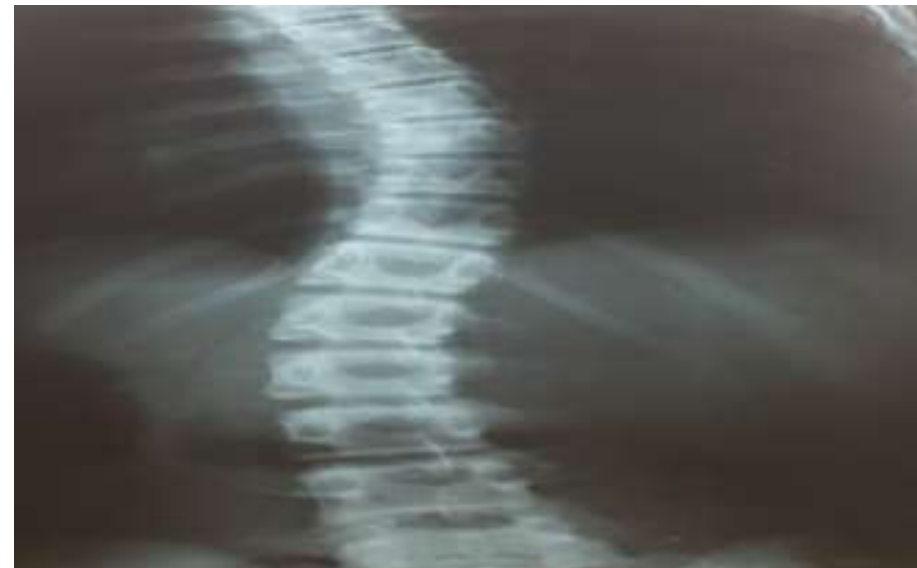

Fig.4X-Ray of vertebral column showing scoliosis. 


\section{Discussion \& Conclusion}

Goldenhar syndrome is known as oculoauriculo vertebral dysplasia. It is proposed to represent avariant of hemifacialmicrosomia group. It includes hemifacial hypoplasia, oculoauriculo vertebral dysplasia and first and second arch syndrome. The involvement is unilateral in $70 \%-80 \%$ of $\operatorname{cases}^{4,12}$. Ocular manifestations are limbaldermoid or lipodermoid and occasional coloboma of the upper eye lid. Limbaldermoid is more common than lipodermoid. It is usually present in the inferotemporal quadrant and can be bilateral in $25 \%$ cases $^{9}$. There are two types of limbaldermoid - large and small. The larger one interferes with the visual axis causing astigmatism and predisposing to secondary strabismus from anisometropic amblyopia. Other associations are Duane Retraction syndrome and lower incidence of decreased corneal sensation; cataract and iris abnormalities $^{13,14}$. Ear tags are common. Inner ear anomalies are occurring in some cases.

CNS is occasionally affected. Vertebral anomalies include kyphosis, scoliosis and lumber lordosis. Other findings include hemifacial asymmetry microtia, macrosomia and mandibular anomalies. Clinical diagnosis is based on the clinical findings and other laboratory and radiological findings ${ }^{15}$.

Treatment of the disease varies according to the severity of the manifestation. With regard to the rule of ophthalmology is aimed-First at risk causing obstruction of the visual axis, severe astigmatism or strabismus, Second at ocular exposure (due to large coloboma or large limbaldermoid preventing lid closure), Third at working with craniofacial surgeon in case of severe muscular weakness that requires reconstruction of the upper face. Systemic treatment may be related for cardio-renal or CNS malformation ${ }^{16}$.

Treatment of the condition related to large coloboma requires surgical repair and spectacle correction, large limbaldermoid needs excision of the dermoid with lamellar keratoplasty. Severe anomalies of the mandible require reconstruction with bone graft. In case of microtia or other ear defects extensive ear reconstruction is to be done within 6-8 years of age ${ }^{14}$. If the facial or congenital malformations are severe speech therapy is required $^{15}$. In this particular case there were anomalies of eye and ear that was corrected by surgical intervention without any complications.

Goldenhar syndrome is a rare congenital abnormality associated with cosmetically unacceptable defects whose management may pose numerous challenges and requires a multistage and multidisciplinary approach for its optimal management.

\section{References}

[1]. Jack J Kanaski, Clinical Ophthalmology, 5th edition, Butterworth's London, 2005: Page 92, 607.

[2]. Vinay C, Reddy RS, Uloopi KS, Madhuri V, Sekhar RC (2009) Chandra Craniofacial features in Goldenhar syndrome. J Indian SocPedod Prevent Dent 27: 121-124.

[3]. Mahore A, Dange N, Nama S, Goel A (2010) Facio-auriculo-vertebro-cephalic spectrum of Goldenhar syndrome. Neurol India 58: $141-144$

[4]. Basic AAO and clinical science course, 2003-2004, Section- 6, Page 391-92

[5]. Bayraktar S, Bayraktar ST, Ataoglu E, Ayaz A, Elveli M. Goldenhar's syndrome associated with multiple congenital abnormalities. J Trop Pediatric. 2005; 51(6):377-9.

[6]. Beck AE, hudgins L, Hoyme HE. Autosomal dominant Microtia and ocular coloboma: new syndrome or an extension of the oculoauriculo-vertebral spectrum? Am J Med Genet 2005; 1; 134(4):359-62.

[7]. Cohen J, Schanen NC. Branchial cleft anomaly, congenital heart disease, and biliary atresia: Goldenhar complex or Lambert syndrome? Genet Couns. 2000; 11(2):153-6.

[8]. Gorlin RJ, Jue KL, Jacobsen U, Goldschmidt E. Oculo-auriculovertebral dysplasia. J Pediatr.1963; 63:991-999

[9]. Goldenhar M. Associations malformatives de l'oeil etl'oreille, en particulier le syndrome dermoideepibulbaire-appendices auriculaires-fistula auris congenital etses relations avec la dysostosemandibulo-fistula auriscongenita et ses relations avec la dysostosemandibulo-faciale. J Genet Hum1952; 1:243-282.

[10]. Sharma JK, Pippal SK, Raghuvanshi SK, Shitij A (2006) Goldenhar-Gorlin's syndrome: A case report. Indian J Otolaryngol Head Neck Surg 58: 97-101.

[11]. "OculoauriculovertebralDysplasis." Online Mendelian inheritance in Man. www. ncbi.nlm.nih.gov/entrez/entrez/ dispomim. cgi?id=164210.

[12]. Schaefer, Bradley G, Olney A, Kolodziej P. Oculoauriculovertebral Spectrum. ENT-Ear, Nose \& throat Joumal. 1998; 77:17-18.

[13]. Singer SL, Haan E, Slee J, Goldblatt J. Familial hemifacialmicrosomia due to autosomal dominant inheritance. Case reports. Aust Dent J. 1994; 39(5):287-91.

[14]. Tasse C, hohringer S, Fisher S, Ludecke HJ, Albrecht B, et al. Oculo-auriculo-vertebral spectrum (OAVS): clinical evaluation and severity scoring of 53 patients and proposal for a new classification. Eur J Med Genet. 2005; 48(4):397-411.

[15]. Tewfik TL, AlnouryK1;Manifestations of Craniofacial Syndromes; eMedicine, October 2008.

[16]. Stoll C, Viville B, Treisser A, Gasser B. A family with dominant oculoauriculovertebral spectrum. Am J Med Genert. 1998; 78(4):345-9. 